\title{
Determination of Ochratoxin A Levels in Mixed Feed and Feed Stuffs Used in Some Laying Hens and Ruminant Enterprises of Sivas City
}

\section{-Author(s)}

\section{Gumus R \\ Ercan N"}

Imik HIII

Department of Animal Nutrition and Nutritional Disorders, Faculty of Veterinary Medicine, Cumhuriyet University, Sivas, Turkey.

" Department of Biochemistry, Faculty of Veterinary Medicine, Cumhuriyet University, Sivas, Turkey.

II Department of Animal Nutrition and Nutritional Disorders, Faculty of Veterinary Medicine, Ataturk University, Erzurum, Turkey.

\section{-Mail Address}

Corresponding author e-mail address Asst. Prof. Recep Gumus

Department of Animal Nutrition and Nutritional Disorders, Faculty of Veterinary Medicine, Cumhuriyet University, Sivas, Turkey.

Tel: $\quad$ +90346219 1010-2597

Email: recepgumus58@hotmail.com

\section{- Keywords}

Feedstuffs, laying hen feed, Mixed feed, Ochratoxin A, Sivas.

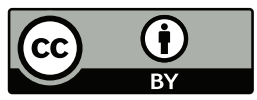

Submitted: 08/June/2017

Approved: 12/October/2017

\section{ABSTRACT}

Mycotoxins, which are produced by some fungi under improper storage conditions before or after harvesting in plant products, cause acute or chronic toxicities. Ochratoxin A (OA) which is also one of the harmful mycotoxins pose a threat to animal and human health. This study was carried out in order to determine OA levels in mixed feed and feedstuffs materials used in livestock enterprises throughout Sivas province. The 59 mixed feeds and 30 feedstuffs materials collected from different enterprises was analysed. Ochratoxin A concentrations were quantified using immunoassay (ELISA). In result, OA was found to be positive in $64(71.91 \%)$ of the 89 samples analysed, whereas OA was not found in 25 samples (28.09\%).

\section{INTRODUCTION}

Mycotoxins produced by fungi are highly toxic and cause acute or chronic mycotoxicosis in animals consuming feeds contaminated with such compounds (Pfohl-Leszkowicz \& Manderville, 2007). It was found that plant-derived feedstuffs may be contaminated with mycotoxins before and after harvesting, and mycotoxins have been found in animal products and in egg, milk and dairy products from animals fed with rations containing such feedstuffs (Hussein \& Brasel, 2001; Meucci et al., 2010). It has been reported that OA contamination in plantbased feedstuffs vary during the year due to climate, water content and storage (Jørgensen et al., 1996).

Ochratoxins are mycotoxins, which are produced by Aspergillus and Penicillium fungi and have three derivatives as A, B and C (Girgin, 2001; Milićević et al., 2010). Ochratoxin A and Ochratoxin B, which is less toxic, were first described by South African chemists in 1965 (Bayman et al., 2002; Castella et al., 2002). Ochratoxin A (OA), one of the mycotoxins commonly found in feedstuffs, is eliminated from the body through urine (Li et al., 1997), feces (Madhyastha et al., 1992) and milk (Breitholz-Emanuelsson et al., 1993). The threshold value for OA in our country was determined as $0.25 \mathrm{ppm}$ in cereal and cereal products; 0.1 ppm in complete and complementary feeds of poultry and $0.05 \mathrm{ppm}$ in compete and complementary feeds of pig (Official Gazette, 2014). In a study conducted, OA was shown to reduce feed consumption, weight gain, and egg yield in birds (Hamilton et al., 1982; Gibsonet al., 1989). It has also been reported that 0.34 and $1.68 \mathrm{mg} \mathrm{OA} / \mathrm{kg}$ body weight in rat's feed (Dortant et al., 2001), 0.5-2 mg / kg in chicken's feed (Singh et al., 1990) and $2.5 \mathrm{mg} / \mathrm{kg}$ in pig's feed (Harvey 1992) pressurizes the immune system. In ruminants, OA toxicity is lower than the ones with a single stomach due to microbial activity in the anterior stomach (Höhler et al., 1999). In fact, it was reported that the dose of $14 \mu \mathrm{g} / \mathrm{kg}$ body weight OA does not show any clinical symptoms and toxicities in sheep 
(Blank et al., 2004). Furthermore, OA was found to be carcinogenic, immunotoxic and nephrotoxic in many different species (Pfohl-Leszkowicz \& Manderville, 2007; El Khoury \& Atoui, 2010).

This study was carried out to determine the contamination of Ochratoxin A in various mixed feed and feedstuffs materials used in livestock enterprises throughout Sivas city.

\section{MATERIAL AND METHODS}

\section{Collection of Feed and Feedstuffs Samples}

Due to its geographical location, the hottest times of the year are during the summer season in Sivas province. For this reason, samples (59 mixed feeds and 30 feedstuffs materials) collected from the randomly selected livestock enterprises in the province in July and August 2016 were gathered according to a method determined by Ergun et al. (2007). Mixed feed samples consisted of calf growth $(n=10)$, cattle fattening $(n=23)$, dairy cow $(n=20)$ and laying hen $(n=6)$ feeds, while feedstuffs material samples consisted of cottonseed meal $(n=12)$, sunflower meal $(n=10)$, soybean meal $(n=3)$ and wheat bran $(n=5)$. The samples taken from storage at the enterprises were kept at $+4^{\circ} \mathrm{C}$ in the refrigerator and analysed within one week when the sample collection work was finished (samples were kept in the refrigerator for a maximum of 60 days).

\section{Biochemical Analyses}

Levels of Ochratoxin $A$ in feed samples were determined by ELISA device (Multiskan, Thermo Fisher Scientific, USA) using the commercial kit (RIDASCREEN, Art No: R1311) via the competitive inhibition enzyme immunoassay method based on the manufacturer's procedure. Limit of detection for feed $2.5 \mathrm{ppb}$ as the described method according to Elisa kit procedure(RBiopharm, 2016).

For preliminary processing of feed samples; 5 grams were weighed and taken from each sample. Each sample with an addition of $100 \mathrm{ml}$ of $0.13 \mathrm{M}$ sodium hydrogen carbonate buffer was vortexed and mixed for 15 minutes. It was centrifuged at room temperature (NF 800 R, Nüve, Ankara, Turkey) for 15 minutes at $3500 \mathrm{~g}$. 50 $\mathrm{\mu l}$ taken from each pre-processed sample was added to the wells. They were incubated for 30 minutes at room temperature and in a dark place by adding $50 \mu \mathrm{l}$ of conjugate enzyme. After the laundering process, substrate was added and then absorbance was detected at $450 \mathrm{~nm}$ wavelength by incubating for 15 minutes under the same conditions.

\section{Statistical Analysis}

SPSS 20.00 statistical package program was used to determine mean, minimum and maximum values of obtained data (SPSSChicago, 2011).

\section{RESULTS}

Of the 89 samples analysed, 64 of them (71.91\%) were found to have OA, while $25(28.09 \%)$ of them were not found to have OA (Table 1). Throughout the 59 samples of mixed feed analysed for Ochratoxin A; OA contamination was found higher than 5-19 ppb in 26 samples (44.07\%), 20-40 ppb in 12 samples $(20.34 \%)$ and $>40 \mathrm{ppb}(10.17 \%)$ in 6 samples. The samples of mixed feed in $15(25.42 \%)$ did not detect ochratoxin A (Table1). During the analysis of the feedstuffs materials, OA contamination was found 5-19 ppb (43.33\%) in 13 samples, 20-40 ppb in 4 samples (\%13.33) and $>40 \mathrm{ppb}$ in 3 of the samples $(10.00 \%)$. The samples of feedstuffs in $10(33.33 \%)$

Table 1 - The ochratoxin a levels in mixed feeds and feedstuffs, \%

\begin{tabular}{|c|c|c|c|c|c|c|c|c|c|}
\hline \multirow{2}{*}{ Feeds } & \multirow[b]{2}{*}{$\mathrm{n}$} & \multicolumn{2}{|c|}{ Undetected } & \multicolumn{2}{|c|}{ 5-19 ppb } & \multicolumn{2}{|c|}{$20-40 \mathrm{ppb}$} & \multicolumn{2}{|c|}{$>40 \mathrm{ppb}$} \\
\hline & & $n$ & $\%$ & $n$ & $\%$ & $n$ & $\%$ & $n$ & $\%$ \\
\hline \multicolumn{10}{|l|}{ Mixed Feeds } \\
\hline Calf growth feed & 10 & 3 & 30.00 & 6 & 60.00 & 1 & 10.00 & 0 & - \\
\hline Cattle fattening feed & 23 & 6 & 26.09 & 9 & 39.13 & 5 & 21.74 & 3 & 13.04 \\
\hline Dairy cow feed & 20 & 4 & 20.00 & 10 & 50.00 & 4 & 20.00 & 2 & 10.00 \\
\hline Laying hen feed & 6 & 2 & 33.33 & 1 & 16.67 & 2 & 33.33 & 1 & 16.67 \\
\hline \multicolumn{10}{|l|}{ Feedstuffs } \\
\hline Cottonseed meal & 12 & 5 & 41.67 & 4 & 33.33 & 1 & 8.33 & 2 & 16.67 \\
\hline Sunflower meal & 10 & 2 & 20.00 & 5 & 50.00 & 2 & 20.00 & 1 & 10.00 \\
\hline Soybean meal & 3 & 1 & 33.33 & 1 & 33.33 & 1 & 33.33 & 0 & - \\
\hline Wheat bran & 5 & 2 & 40.00 & 3 & 60.00 & 0 & - & 0 & - \\
\hline Mixed Feeds & 59 & 15 & 25.42 & 26 & 44.07 & 12 & 20.34 & 6 & 10.17 \\
\hline Feedstuffs & 30 & 10 & 33.33 & 13 & 43.33 & 4 & 13.33 & 3 & 10 \\
\hline Total & 89 & 25 & 28.09 & 39 & 43.82 & 16 & 17.98 & 9 & 10.11 \\
\hline
\end{tabular}


did not detect OchratoxinA (Table1). The mean, minimum and maximum values of mixed feed and feedstuffs materials are given in Table 2 .

Table 2 - The levels of average, minimum and maximum ochratoxin in mixed feed and feedstuff (ppb).

\begin{tabular}{lcccc}
\hline Feeds & $\mathrm{n}$ & $\mathrm{X} \pm \mathrm{SX}$ & Minimum & Maximum \\
\hline Mixed Feeds & & & & \\
Calf growth feed & 10 & $8.09 \pm 2.20$ & 6.20 & 18.90 \\
Cattle fattening feed & 23 & $28.36 \pm 10.22$ & 5.60 & 222.40 \\
Dairy cow feed & 20 & $35.46 \pm 15.92$ & 7.80 & 305.60 \\
Laying hen feed & 6 & $27.28 \pm 14.96$ & 8.40 & 96.30 \\
\hline Feedstuffs & & & & \\
Cottonseed meal & 12 & $28.36 \pm 14.15$ & 9.50 & 157.20 \\
Sunflowermeal & 10 & $20.58 \pm 8.28$ & 7.20 & 89.10 \\
Soybean meal & 3 & $14.00 \pm 10.43$ & 7.60 & 34.40 \\
Wheat bran & 5 & $5.82 \pm 2.72$ & 6.80 & 14.50 \\
\hline
\end{tabular}

$\mathrm{X} \pm \mathrm{Sx}$ : mean \pm Standard error

\section{DISCUSSION}

Ochratoxin $A$ is a very important toxin due to its frequent presence in nature and the pathological conditions it causes. When unprocessed agricultural products contaminated with Ochratoxin A are used as feed, they do not cause problems in ruminant adult animals; it may contaminate the meat products of nonruminant animals such as pigs and poultry (Walker \& Christian Larsen, 2005). In ruminants, protozoa and bacterial enzymes in the anterior stomach hydrolyze $\mathrm{OA}$, resulting in phenylalanine and non-toxic OT $\alpha$ formation (Battacone et al., 2010; Mobashar et al., 2012). However, enzymes involved in the metabolism of phenylalanine indirectly have adverse effects on lipid peroxidation and mitochondrial respiration (Steyn \& Stander, 1999).

According to the communiqué published in our country on April 19, 2014, 0.25 ppm in cereal and cereal products, $0.1 \mathrm{ppm}$ in poultry complete and supplementary feeds and $0.05 \mathrm{ppm}$ in pigs complete and supplementary feeds were determined, although the values of ochratoxin in the feeds vary according to the countries (Official Gazette, 2014). In our study, the ratio of OA found was $74.58 \%$ in mixed feeds and $66.67 \%$ in feedstuffs materials (Table 1). While these results are lower than the limit values that OA is allowed to be found in feeds, it may lead to a loss of yield and health problems in animals after such consumption of feeds for a long time (Moura et al., 2004). In a study conducted in our country, the ratio of OA found was $66.67 \%$ in mixed feeds, while it was $47.83 \%$ in feedstuffs materials (Yıldız, 2009). In another study, it was found that $18.2 \%$ of the 302 mixed feeds, feedstuffs and food samples taken from 25 different feed plants in 7 different geographical regions of Turkey contained $\mathrm{OA}$ and $21.4 \%$ of these samples had $10-20$ ppb of OA, $23.4 \%$ of them had 20-40 ppb of OA and $55.2 \%$ of them had higher than 40 ppb (Ozkazanc et al., 1992). In a study by Araguás et al. (2005), 72 different cereal crops were analysed and although $79 \%$ of the samples were found to have OA contamination only 2 samples were above the allowed limit value. In a similar study, 91 grain products were analysed and it was determined that only 1 sample had OA above the allowed value (Vega et al., 2009). In a study by Altintas et al. (2011), it was found that only 2 out of 56 samples had OA above the allowed limit.

Although cattle were shown to be more resistant to mycotoxin-induced toxicity than other animal species due to their stomach structure, chronic toxicities were observed in some dairy cattle (Whitlow \& Hagler, 2004). It was reported that such toxicities did not have a specific symptom but there may be a decrease in milk yield or susceptibility to diseases and that inflammation and oedema were found especially in the intestines in the pathological examination performed (Whitlow \& Hagler, 2004; Whitlow \& Hagler, 2005). In our study, the samples taken from calf growth, cattle fattening and dairy cow feedstuffs, respectively contained $70.0 \%, 73.91 \%$ and $80.00 \%$ of OA above $5 \mathrm{ppb}$ levels (Table 1). In a survey of feed samples collected from different regions in Turkey, it was reported that OA level was above $5 \mathrm{ppb}$ in $66.66 \%$ of calf growth feed, $55.17 \%$ of cattle fattening feed and $60.00 \%$ of dairy cattle feed (Yıldız, 2009). Rosa et al. (2008) determined that OA positive of $25 \%$ for finished cow's feed, $31 \%$ for maize and $22 \%$ for barley rootlets. When compared to the results of this study, it is seen that there are more samples containing OA in terms of percentage in our study. Accordingly, it can be said that the contamination in the feeds continues at a low level but still has a high rate.

In mixed feed samples $(n=27)$ taken from poultry farms in and around Bursa province, the coincidence rate of OA was reported to be $100 \%(4.36 \pm 0.46 \mathrm{ppb})$ (Sonal \& Oruc, 2000). Yıldız (2009) stated that OA level was $18.43 \pm 3.19 \mathrm{ppb}$ in $75 \%$ of the laying hen feeds. In our study, $66.67 \%$ of laying hen mixed feed samples $(n=6)$ contained OA above $5 \mathrm{ppb}$, but the quantities found were below $0.1 \mathrm{ppm}$, the limit value allowed to be found in poultry feeds according to the communiqué issued on 19 April 2014 (Official Gazette, 2014). However, it is known that the likelihood of 
a single mycotoxin being present in a feed is very low, and it is generally known that the same fungus species can synthesize many mycotoxins and fungi that produce different mycotoxins (Hussein \& Brasel, 2001) can easily infest this feed. For these reasons, the likelihood of other toxins existence in poultry feed is considered when the OA existence is high; there is a high possibility of seeing cases such as decrease in performance, weakening of immunity system and susceptibility to diseases in animals fed with these feeds.

In our research, OA was higher than 5 ppb levels respectively in $58.33 \% ; 80.00 \%$; $66.66 \%$ and $60.00 \%$ of the feedstuffs materials such as cottonseed meal, sunflower meal, soybean meal and wheat bran (Table 1). In a similar study, it was determined that the OA level was above $5 \mathrm{ppb}$ in $50.00 \%$ of the cottonseed meal samples, $56.25 \%$ of the sunflower meal samples, $33.33 \%$ of the soybean meal samples and $16.67 \%$ of the bran samples (Yıldız, 2009). In a study in Sudan, in feeds like crushed sorghum (0.33$1.58 \mu \mathrm{g} / \mathrm{kg})$, sunflower cake $(1.59 \mu \mathrm{g} / \mathrm{kg})$, wheat bran $(0-0.43 \mu \mathrm{g} / \mathrm{kg})$ and groundnut cake $(0-0.31 \mu \mathrm{g} / \mathrm{kg}) \mathrm{OA}$ contamination was found (Elzupir et al., 2009). Also in a study in Romania, it was found that 34.6 out of 52 samples had OA positive (avarage $6.39 \mathrm{mg} / \mathrm{kg}$ ) (Alexa et al., 2013). In a study by Kaya et al. (1990) ( $n=20)$, soybean $(n=9)$, cottonseed meal $(n=11)$ and sunflower meal $(n=11)$ were used as feedstuffs in the research they carried out. As a result of the study, OA was determined in 1 corn and 6 sunflower meal samples, and the amount of OA was $260 \mathrm{ppb}$ in corn and 200$800 \mathrm{ppb}$ in sunflower meal and $438 \mathrm{ppb}$ on average. The results of the study by Kaya et al. (1990) are quite high compared to our results, which are thought to be due to factors such as regional differences, climate, relative air humidity and mechanical injury (Jørgensen et al., 1996; Erzurum, 2001).

\section{CONCLUSIONS}

In the feed samples analysed, it was found that the quantities of Ochratoxin A were below the allowed value for feeds. Microbial contamination in feedstuffs can be avoided by hygiene and sanitation measures during crop harvesting and subsequent processes and by ensuring adequate environmental conditions (humidity, temperature, etc.) during storage. Nevertheless, it is thought that it would be useful to carry out routine analyses of coarse and concentrated feeds given to animals in terms of mycotoxins.

\section{REFERENCES}

Alexa E, Dehelean CA, Poiana MA, Radulov I, Cimpean AM, Bordean DM, et al. The occurrence of mycotoxins in wheat from western Romania and histopathological impact as effect of feed intake. Chemistry Central Journal 2013;7(1):99.

Altintas L, Ekici H, Yarsan E, Cakır S, Evrensel MF, Tokgoz BS. Investigation of the total aflatoxin, aflatoxin $B 1$ and ocratoxin $A$ residues in the ruminant and poultry feeds obtaiend from Ankara, Konya and Bolu. Journal of Etlik Veterinary Microbiology 2011;22(2):61-67.

Araguás C, González-Peñas E, Cerain AL. Study on ochratoxin A in cerealderived products from Spain. Food Chemistry 2005;92(3):459-464.

Battacone G, Nudda A, Pulina G. Effects of ochratoxin A on livestock production. Toxins 2010;2(7):1796-1824

Bayman P, Baker JL, Doster MA, Michailides TJ, Mahoney NE. Ochratoxin production by the Aspergillus ochraceus group and Aspergillus alliaceus. Applied and Environmental Microbiology 2002;68(5):23262329.

Blank R, Rolfs JP, Sudekum KH, Frohlich AA, Marquardt RR, Wolffram S Effect of roughage:concentrate ratio in the diet on systemic availability and excretion of ochratoxin $A$ in sheep. Journal of Animal and Feed Sciences 2004;13(Suppl. 1):673-676.

Breitholz-Emanuelsson A, Olsen M, Oskarsson A, Palminger I, Hult K. Ochratoxin in cow's milk and in human milk with corresponding human blood samples. Journal of AOAC International 1993;76(4):842-846.

Castella G, Larsen TO, Cabanes J, Schmidt H, Alboresi A, Niessen L, et al. Molecular characterization of ochratoxin A producing strains of the genus Penicillium. Systematic and Applied Microbiology 2002;25(1):7483.

Dortant PM, Peters-Volleberg GWM, Van Loveren H, Marquardt RR, Speijers GJA. Age-related differences in the toxicity of ochratoxin A in female rats. Food and Chemical Toxicology 2001;39(1):55-65.

El Khoury A, Atoui A. Ochratoxin A: general overview and actual molecular status. Toxins 2010;2(4):461-493

Elzupir AO, Makawi SZ, Elhussein AM. Determination of anatoxins and ochratoxin a in dairy cattle feed and milk in wad medani, Sudan. Journal of Animal and Veterinary Advances 2009;8(12):2508-2511.

Ergun A, Tuncer SD, Colpan I, Yalcın S, Yıldız G, Kucukersan MK, et al. Feeds, feed hygiene and technology. $3^{\text {rd }}$ ed. Ankara: Positive Press; 2007. p.309-312.

Erzurum $\mathrm{K}$. The factors effecting mycotoxin formation in food. The Journal of Food 2001;26(4):289-293.

Gibson RM, Bailey CA, Kubena LF, Huff WE, Harvey RB. Ochratoxin A and dietary protein. 1. Effects on body weight, feed conversion, relative organ weight, and mortality in three-week-old broilers. Poultry Science 1989;68(12):1658-1663.

Girgin G. Mycotoxins in turkey and the world. Turkish Bulletin of Hygiene and Experimental Biology 2001;58(3):97-118.

Hamilton PB, Huff WE, Harris JR, Wyatt RD. Natural occurrences of ochratoxicosis in poultry. Poultry Science 1982;61(9):1832-1841.

Harvey RB, Elissalde MH, Kubena LF, Weaver EA, Corrier DE, Clement BA. Immunotoxicity of ochratoxin A to growing gilts. American Journal of Veterinary Research 1992;53(10):1966-1970.

Höhler D, Südekum K-H, Wolffram S, Frohlich AA, Marquardt RR Metabolism and excretion of ochratoxin A in sheep. Journal of Animal Science 1999;77(5):1217-1223. 
Hussein HS, Brasel JM. Toxicity, metabolism, and impact of mycotoxins on humans and animals. Toxicology 2001;167(2):101-134.

Jørgensen K, Rasmussen G, Thorup I. Ochratoxin A in Danish cereals 1986 - 1992 and daily intake by the danish population. Food Additives \& Contaminants 1996;13(1):95-104

Kaya S, Yavuz H, Akar F. Mycotoxin residues in some oily seed meals. Veterinary Journal of Ankara University 1990;37(1):173-180.

Li S, Marquardt RR, Frohlich AA, Vitti TG, Crow G. Pharmacokinetics of ochratoxin $A$ and its metabolites in rats. Toxicology and Applied Pharmacology 1997;145:82-90.

Madhyastha MS, Marquardt RR, Frohlich AA. Hydrolysis of ochratoxin A by the microbial activity of digesta in the gastrointestinal tract of rats. Archives of Environmental Contamination and Toxicology 1992;23(4):468-472

Meucci V, Razzuoli E, Soldani G, Massart F. Mycotoxin detection in infant formula milks in Italy. Food Additives and Contaminants 2010;27(1):6471.

Milićević $D$, Jurić $V$, Stefanović $S$, Baltić T, Janković $S$. Evaluation and validation of two chromatographic methods(HPLC-Fluorescence and LC-MS/MS) for the Determination and confirmation of ochratoxin A in pig tissues. Archives of Environmental Contamination and Toxicology 2010;58(4):1074-1081.

Mobashar M, Blank R, Hummel J, Westphal A, Tholen E, Südekum KH. Ruminal ochratoxin A degradation-Contribution of the different microbial populations and influence of diet. Animal Feed Science and Technology 2012;171(2):85-97.

Moura MA, Machado CH, Porfirio LC, Freire RB. Effects of ochratoxin a on broiler leukocytes. Revista Brasileira de Ciência Avícola 2004;6(3):187190.

Official Gazette. Communiqué on unwanted materials in feeds. Official Gazette; 2014 April 19. (Communiqué, 2014/11).

Ozkazanc AN, Russel-Sin H, Sanlı Y, Kaya S. The Investigation of the polludon status arislog from inycotoxms in the mixed feeds and feedstaHs produced lo various region of Turkey. Veterinary Journal of Ankara University 1992;39(1-2):268-290.
Pfohl-Leszkowicz A, Manderville RA. Ochratoxin A: an overview on toxicity and carcinogenicity in animals and humans. Molecular Nutrition \& Food Research 2007;51(1):61-99.

R-Biopharm. Ridascreen® test kits. Darmstadt: RBiofarm AG; 2016.

Rosa C, Cavaglieri L, Ribeiro J, Keller K, Alonso V, Chiacchiera S, et al. Mycobiota and naturally-occurring ochratoxin $A$ in dairy cattle feed from Rio de Janeiro State, Brazil. World Mycotoxin Journal 2008;1(2):195-201.

Singh GSP, Chauhan HVS, Jha GJ, Singh KK. Immunosuppression due to chronic ochratoxicosis in broiler chicks. Journal of Comparative Pathology 1990;103(4):399-410.

Sonal S, Oruc HH. Natural mycotoxin levels in mixed feed taken from poultry farm in Bursa Province.Van Veterinary Journal 2000;2:1-6.

SPSS. Statistical packages for the social sciences. $20^{\text {th }}$ ed. Chicago: IBM Inc; 2011.

Steyn PS, Stander MA. Mycotoxins with special reference to the carcinogenic mycotoxins: aflatoxins, ochratoxins and fumonisins. In: Ballantyne B, Marrs TC, Syversen TLM, editors. General and applied toxicology. $2^{\text {nd }}$ ed. United Kingdom: Macmillan Reference; 1999. p.2145-2176.

Vega M, Munoz K, Sepulveda C, Aranda M, Campos V, Villegas R, et al. Solid-phase extraction and HPLC determination of Ochratoxin A in cereals products on Chilean market. Food Control 2009;20:631-634.

Walker R, Christian Larsen J. Ochratoxin A: previous risk assessments and issues arising. Food Additives and Contaminants 2005;22(supl 1):6-9.

Whitlow LW, Hagler WM. Mycotoxins in feeds. Feedstuffs 2004;76(38):6676.

Whitlow LW, Hagler WM. Mycotoxins in dairy cattle: occurence, oxicity, prevention and treatment. Proceedings of the Southwest Nutrition Conference; 2005; El Centro, Californa: Desert Researcu Center; 2005. p.124-138.

Yıldız G. Determination of the contamination of the ochratoxine $A$ in feeds and feedstuffs into the different animal enterprise in Turkey. Veterinary Journal of Ankara University 2009;56:131-135. 
